\title{
Dispersal distances for propagules of Sargassum spinuligerum (Sargassaceae, Phaeophyta) measured directly by vital staining and venturi suction sampling
}

\author{
Gary A. Kendrick, Diana I. Walker \\ Department of Botany, University of Western Australia, Nedlands, WA 6009, Australia
}

\begin{abstract}
Dispersal of propagules from fertile thalli of Sargassum spinuligerum was measured in situ using a novel technique. Propagules were stained with Toluidine Blue while still attached to parent thalli. After $24 \mathrm{~h}$, the density of settled propagules was determined at different distances from the stained thalli with a venturi suction sampler. Previous measurements of propagule or spore dispersal have not differentiated sources, measured only distances of dispersal outside existing stands of marine algae, and combined propagule dispersal and settlement patterns with post-settlement survival. However, the technique described here allows direct measurement of propagule dispersal in marine algae. Dispersal of propagules was highly localized. Numbers of recovered stained propagules differed between November and December 1990 and these differences are assumed to reflect different levels of release. The December study had a greater total number of recovered propagules (approximately 100000 versus 12000 collected in November) and a more rapid decline in settlement density with distance (96\% of stained propagules were collected within $0.25 \mathrm{~m}$ of parent thalli). There was an exponential decline in the densities of stained propagules $\left(\mathrm{m}^{-2}\right)$ with distance $-98 \%$ were collected within $1 \mathrm{~m}$ of parent thalli. The localized dispersal pattern observed in this study fits previous descriptions of contagious patterns of recruitment in Sargassum and observed clumping of adults of other fucalean algae.
\end{abstract}

\section{INTRODUCTION}

Dispersal patterns of reproductive spores or propagules of marine algae have been rarely studied (Anderson \& North 1966, Amsler \& Searles 1980, Deysher \& Norton 1982, Reed et al. 1988) as it is difficult to recognize the source of the spore or propagule (Chapman 1985). Settlement plates have been used to estimate dispersal. They are placed in the field for a period of time then returned to the laboratory and cultured (Hruby \& Norton 1979, Hoffman \& Ugarte 1985, Reed et al. 1988). The major weakness of this method is that it combines patterns of dispersal with postsettlement survival rates (recruitment sensu Connell 1985), but no more direct method of measuring dispersal has been reported in the literature. Here we outline a direct method for measuring dispersal of sexually-derived propagules of Sargassum species that relies on staining the propagules at their source.
Unlike the previous method, this technique measures dispersal directly and offers an assessment of dispersal patterns independent of recruitment. With more specific staining or radioactive labelling techniques it could be developed for use with other algae.

Sargassum is a well represented genus world-wide and is common in tropical and warm temperate regions (Womersley 1987). The propagule of Sargassum is a developing zygote. Sargassum expels eggs in a number of pulses over a few days, and this expulsion is loosely associated with the full or new moon (Norton 1981, May \& Clayton 1991). The eggs remain attached to the receptacles and zygotes develop for at least 24 to $48 \mathrm{~h}$ before release (Norton 1981, May \& Clayton 1991). Although most receptacles synchronously release eggs, there is a highly variable number of conceptacles on each receptacle producing eggs, and the time of release of zygotes is variable. For these reasons we have concentrated only on the process of dispersal and 
not attempted to estimate the magnitude of propagule release. These propagules are easily identified in plankton trawls, are larger than most algal spores (120 to $280 \mu \mathrm{m}$ ), and sink rapidly in still water (Deysher \& Norton 1982). These characteristics make the study of propagule dispersal in Sargassum possible. Sargassum is invasive (Critchley et al. 1983, Paula \& Eston 1987) but most propagules appear to settle out of the water column within meters of parents and the greatest distances that propagules have been recorded from their source was $1.7 \mathrm{~km}$ (Deysher \& Norton 1982).

Here we describe a method where propagules were stained with Toluidine Blue while they were still attached to parent thalli of Sargassum spinuligerum. The dispersal of stained propagules was then determined by suction of areas of the bottom with a venturi air lift at varying distances from the stained parents. The main aim in developing this technique was to assess directly patterns of dispersal of $S$. spinuligerum. A variety of stains were tried before deciding on Toluidine Blue. These included Calcofluor White, Auramine-O (Hawes \& Davey 1989), ethidium bromide, Janus Green, Methylene Blue, mercurochrome and Neutral Red. These all did not stain as permanently nor were as recognizable as Toluidine Blue.

\section{MATERIALS AND METHODS}

Reproductive thalli of Sargassum spinuligerum were collected using SCUBA from a subtidal population ( $6 \mathrm{~m}$ depth) at Nancy Cove, Rottnest Island, Western Australia $\left(32^{\circ} 02^{\prime} \mathrm{S}, 115^{\circ} 28^{\prime} \mathrm{E}\right)$ on 25 November and 12 December 1990. There are few, if any, storm events during these months in Western Australia. Prevailing southwesterly winds do produce a small sea which creates surgy conditions at the study area and the direction of surge was included in the sampling design. All reproductive thalli collected had visible zygotes attached to the outside wall of conceptacles and the zygotes were all 32 cells or greater.

Approximately 80 reproductive thalli were tied together with flagging tape and stained in a large bin (30 l) of $0.05 \%$ Toluidine Blue in seawater for 1 to $2 \mathrm{~h}$. They were then returned to the subtidal zone where they were tied in a bundle to a stake within the population of Sargassum. The substratum around the bundle of stained thalli was sampled $24 \mathrm{~h}$ later with a small venturi air lift (Fig. 1). Areas of substratum were 'vacuumed' and their contents collected in a mesh bag (164 $\mu \mathrm{m}$ mesh size). The pattern of sampling radiated from the stained thalli in directions parallel (SW to NE) and perpendicular (SE to NW) to wave direction (Fig. 2). The area of substratum 'vacuumed' expanded

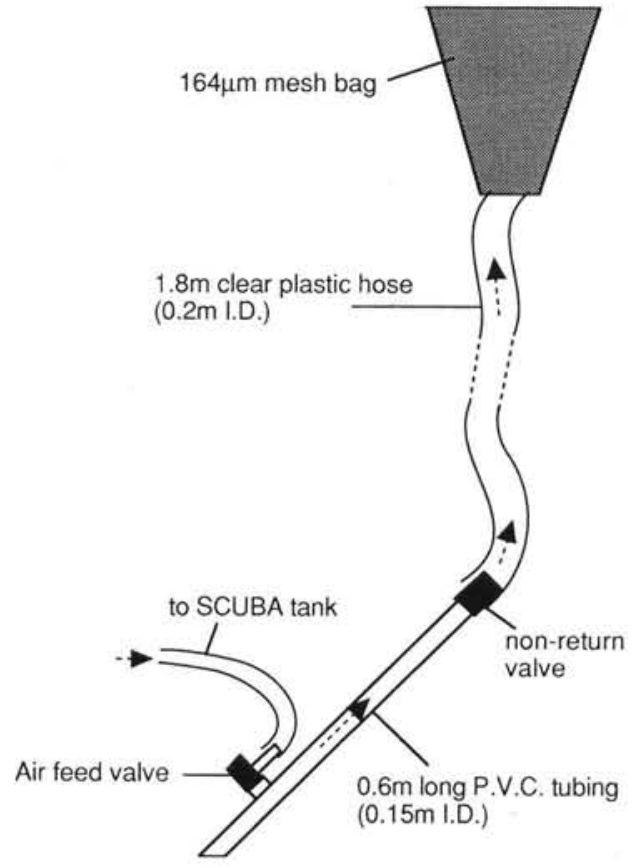

Fig. 1. Schematic of the venturi air lift used in this study showing specifications

with distance from the stained thalli, increasing in proportion to the increase in total area of substratum. Samples of equal area would have biased the sampling in favour of the samples nearest to the stained thalli. Samples from the mesh bags were washed through $1 \mathrm{~mm}$ and $500 \mu \mathrm{m}$ sieves to remove large shell fragments and organic detritus. The finer sands, small animals and Sargassum propagules were then placed in gridded petri dishes under an Olympus dissecting microscope $(100 \times$ magnification). Propagules stained blue by the Toluidine Blue stain were counted. Total stained propagules in each sample were calculated as propagule density $\mathrm{m}^{-2}$. The 4 compass bearings (SW, NE, NW, SE) were grouped together after a 1-way ANOVA showed no significant difference $(p=0.01)$ in settlement patterns of stained propagules with direction.

\section{RESULTS AND DISCUSSION}

Propagules were recovered successfully from the substratum following staining. Most stained propagules of Sargassum spinuligerum dispersed over distances $<1 \mathrm{~m}$ with $98 \%$ of all propagules collected within $1 \mathrm{~m}$ of parent thalli in November and $99 \%$ in December 1990 (Table 1). Propagule densities also declined exponentially with distance from stained parents (Fig. 3). 


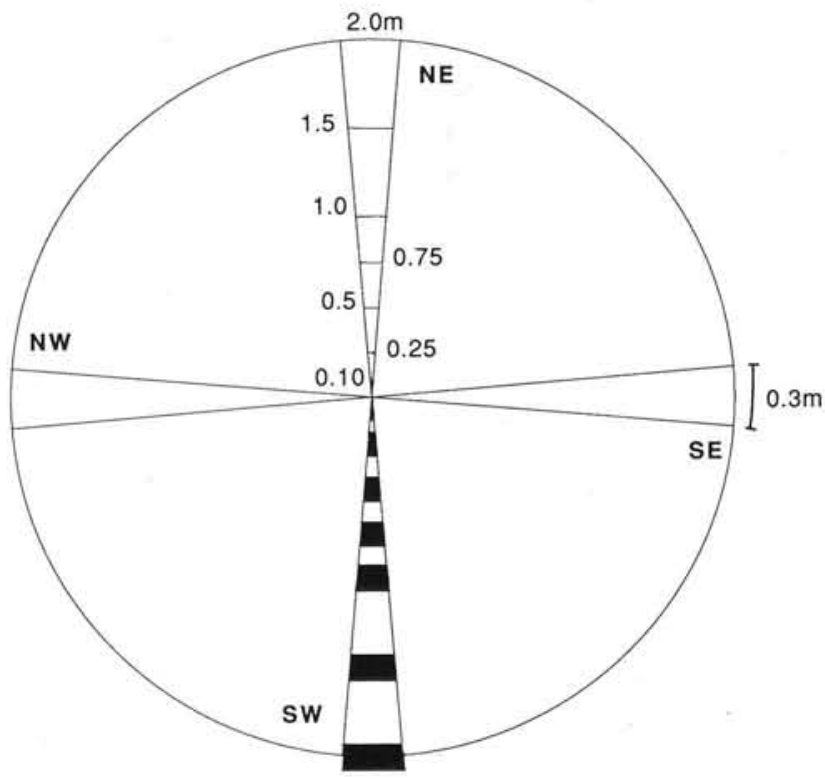

Fig. 2. Sampling design showing the 4 directions sampled, median distances of sampling $(0.10,0.25,0.50,0.75,1.00$, $1.50,2.00 \mathrm{~m}$ radii), and the increasing areas sampled (shown in black) with increasing distance from the stained thalli. Stained thalli are placed in the center

The pattern of propagule dispersal was different between November and December. In November, the total number of retrieved stained propagules was small (11919). The decline in density of stained propagules with distance was gradual: densities at 0.1 and $0.25 \mathrm{~m}$ were similar $(44.7 \%$ and $36.3 \%$ respectively), and $1 \%$ of the total number of stained propagules were found at $1.5 \mathrm{~m}$. The December study had a greater total number of stained, settled propagules (approximately 107000). Settlement density showed a more rapid decline with distance $(96 \%$ of stained propagules were collected within $0.25 \mathrm{~m}$ of parent thalli). The differences in the number of propagules retrieved by the air lift in November and December may be related to the magnitude of propagule release at these times. No attempt was made to determine magnitude of release and it was not possible to control for the staining and attachment of stained thalli subtidally. Therefore, our discussion is concentrated on the differences in the patterns of dispersal between November and December and not on the total number of retrieved propagules. Standard errors were large, over the entire range of distances. As no attempt was taken to sample similar substrata, much of the variation between samples at the same distance could be due to variations in substrata (rock or sand), and cover by other benthic organisms (encrusting sponges and coralline algae, algal turfs, Sargassum).

The pattern of dispersal for Sargassum spinuligerum is comparable to models and observations of air-borne seeds, pollen and spores of terrestrial plants and fungi (Schrodter 1960, Okubo \& Levin 1989). For S. spinuligerum distances of dispersal are at scales of centimeters to meters versus the tens of meters to thousands of kilometers in terrestrial plants and fungi. Studies of wind-borne dispersal have described the shape of the curve that best depicts the relationship between the number of dispersed propagules (seeds, spores) to distance from source. For both November and December, the Inverse Power Law, $y=a^{-b}$ (or in linear form, $\ln y=\ln a-b \ln x$; Gregory 1968), gave the best fit to the data (Fig. 4). Transforming both density of stained propagules and distance stresses the exponential decline in settled propagules with distance from their source. The slopes of regressions, or the decline in settlement density, fitted to the November $\left(y=\mathrm{e}^{5.27} \mathrm{X}^{-1.66}, \mathrm{r}^{2}=0.654, \mathrm{p}<0.0001\right)$ and December $\left(y=\mathrm{e}^{17.79} \mathrm{x}^{-2.71}, \quad \mathrm{r}^{2}=0.949, \mathrm{p}<0.0001\right)$ data were significantly different (Student's $t$-test on slopes: $\mathrm{p}<0.05)$.

Table 1. Sargassum spinuligerum. Mean density and standard error $(n=4)$ of stained propagules $\mathrm{m}^{-2}$ collected at different distances (m) from parent thalli on 25 November and 12 December 1990. Density is also expressed as \% of total stained propagules retrieved over all distances

\begin{tabular}{|c|c|c|c|c|c|c|}
\hline \multirow[b]{2}{*}{$\begin{array}{l}\text { Distance } \\
(\mathrm{m})\end{array}$} & \multicolumn{3}{|c|}{ November 1990} & \multicolumn{3}{|c|}{ December 1990} \\
\hline & $\begin{array}{l}\text { Density (stained } \\
\text { propagules } \mathrm{m}^{-2} \text { ) }\end{array}$ & $\mathrm{SE}(n=4)$ & $\begin{array}{l}\% \text { Total propa- } \\
\text { gules retrieved }\end{array}$ & $\begin{array}{l}\text { Density (stained } \\
\text { propagules } \mathrm{m}^{-2} \text { ) }\end{array}$ & $\mathrm{SE}(n=4)$ & $\begin{array}{l}\% \text { Total propa- } \\
\text { gules retrieved }\end{array}$ \\
\hline 0.10 & 5333 & 1564 & 44.7 & 91500 & 23682 & 85.7 \\
\hline 0.25 & 4323 & $1839^{a}$ & 36.3 & 12262 & 2075 & 11.5 \\
\hline 0.50 & 1223 & 487 & 10.3 & 2424 & 464 & 2.2 \\
\hline 0.75 & 419 & 117 & 3.5 & 303 & 136 & 0.3 \\
\hline 1.00 & 480 & 122 & 4.0 & 196 & 28 & 0.2 \\
\hline 1.50 & 117 & $62^{\mathrm{a}}$ & 1.0 & 80 & 7 & 0.07 \\
\hline 2.00 & 28 & $17^{\mathrm{a}}$ & 0.2 & 28 & 14 & 0.03 \\
\hline Total & 11919 & & 100 & 106793 & & 100 \\
\hline
\end{tabular}



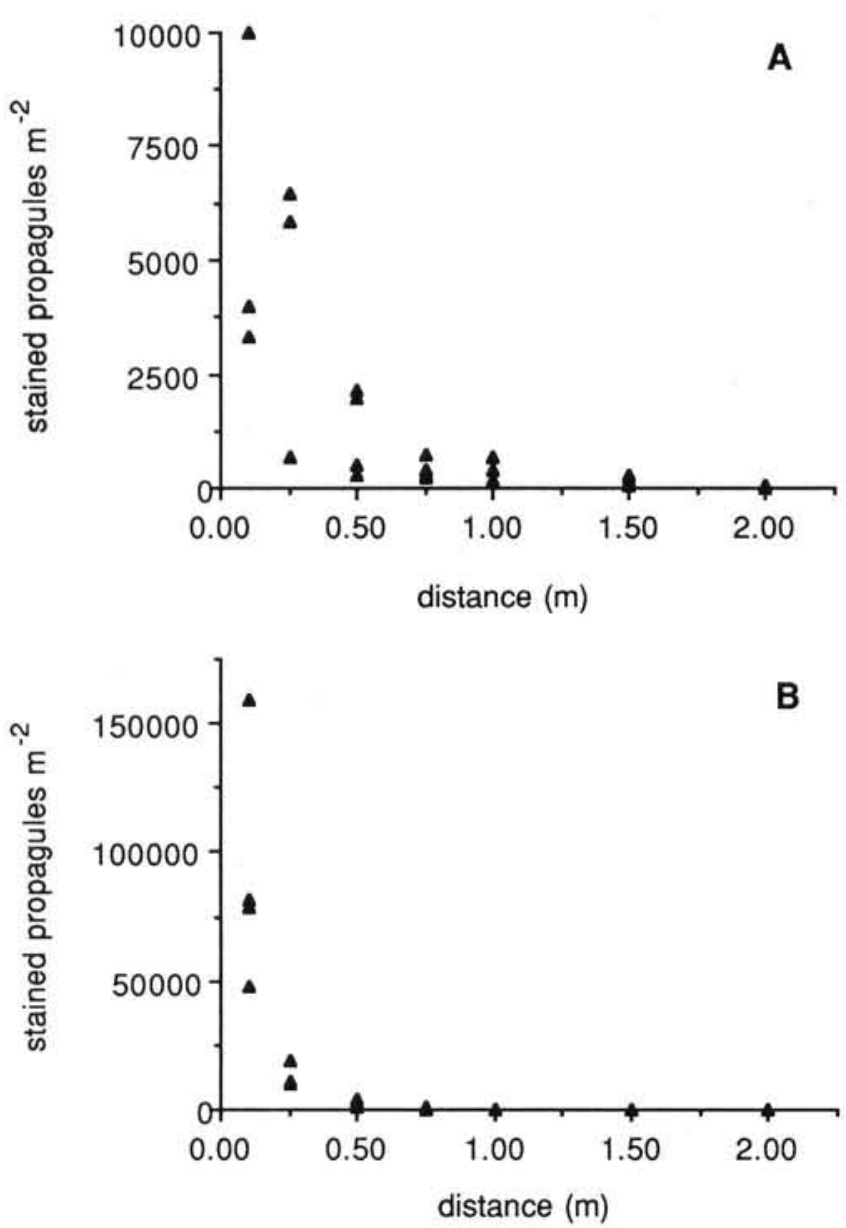

Fig. 3. Exponential decline in stained propagules collected (stained propagules $\mathrm{m}^{-2}$ ) with distance $(\mathrm{m})$ from parent thalli for (A) November and (B) December

From an ecological perspective, a localized dispersal pattern maintains densities of individuals within Sargassum populations. Localized dispersal patterns could also account for dense, local recruitment patterns as shown for S. sinclairii (Schiel 1985) and S. muticum (Deysher \& Norton 1982). Deysher \& Norton (1982) seeded areas with propagules of $S$. muticum from transplanted, reproducing adults and found very dense recruitment within $1 \mathrm{~m}$ of the parents, sparse recruitment up to $3 \mathrm{~m}$ away and a few recruits up to $30 \mathrm{~m}$ away. Our direct observations of propagule dispersal suggests recruitment reported in their study reflects the highly localized dispersal patterns of propagules from the transplanted reproducing adults. Localized dispersal could also be expressed in the distributions of adults. Rice (1987) found the spatial distribution of Xiphophora gladiata to be highly contagious and other researchers have commented on patchy distributions in algae (Sousa 1984, Jernakoff 1985). From a genetic perspective, localized dispersal

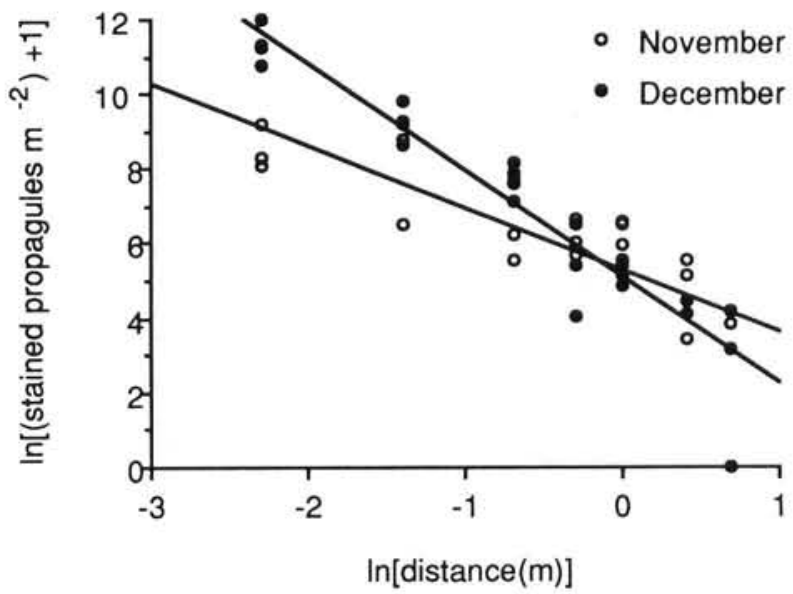

Fig. 4. Plot with both stained propagule density (stained propagules $\mathrm{m}^{-2}$ ) and distance (m) (natural log transformed) showing best fit linear regressions for November and December

acts to localize the genotype which could result in deleterious effects if there is no mechanism controlling inbreeding. Recent work of Rice \& Kenchington (1990) showed adult phenotypes of the fucoid $X$. gladiata to be discontinuous between clumps of thalli over scales of $100 \mathrm{~mm}$. Highly localized dispersal that was effectively within the clumps of Xiphophora could explain their observed pattern. Localized dispersal could also help in the quick establishment of Sargassum populations once individuals have colonized new habitat. Quick establishment of S. muticum has been described from the northeastern Pacific (DeWreede 1983) and European Atlantic (Critchley 1983, Fernandez et al. 1990).

Dispersal of Sargassum from propagules is not restricted to a few meters. Even though the density of propagules settling further from parents is small, successful recruitment may occur. Drifting fragments of thalli have been proposed as a more likely mechanism for long distance dispersal in marine algae (Deysher \& Norton 1982, van den Hoek 1987). However, a single Sargassum can release 1 to $6 \times 10^{6}$ propagules during 1 reproductive season (Umezaki 1984). Here, from 80 thalli during 2 periods of release, we counted only 12000 and 100000 propagules $\mathrm{m}^{-2}$, respectively. Reed et al. (1988) found dispersal distances of kelp zoospores were greatly expanded during episodic events of high recruitment that coincided with winter storms. Propagule release in Sargassum coinciding with storms may also result in greater distances of dispersal. Chance long distance dispersal has been shown to be important in the recruitment and geographical range extension of terrestrial plants (reviewed by Carlquist 1981) and should be investigated further in marine algae. 
There are a few practical comments that should be made about the method. The design only compares settlement densities of stained propagules to distances from their source. No attempt was made to determine the magnitude of propagule release during November and December 1990. It was assumed that patterns of propagule settlement were passive, being mainly influenced by hydrodynamics and not by behaviour. The influence of the stain on the behaviour of the propagule has not been addressed. The methodology is being further refined. More specific stains are being investigated but the major difficulty has been that the $\mathrm{pH}$ of seawater is high for many commonly used stains. Also, at present this methodology is only suitable for small areas of substratum. The small venturi airlift clogs with sand easily. Each sample takes between 2 and $4 \mathrm{~h}$ to analyse. This limits the number of samples that can be processed. The removal of thalli for staining may also have an impact on subsequent release of propagules. There is potential to in situ stain reproductive thalli of Sargassum spinuligerum, but we found staining in situ to be severely constrained by time limitations on SCUBA diving.

\section{CONCLUSIONS}

Staining and venturi air lifting are effective for the direct measurement of patterns of dispersal in Sargassum spinuligerum and with modification may be able to be applied to other species of algae. Dispersal in S. spinuligerum was highly localized and exponential decline in settlement densities occurred over the $2 \mathrm{~m}$ distances we sampled. This localized dispersal pattern fits previous descriptions of contagious patterns of recruitment in Sargassum and clumping of adults of other fucalean algae.

Acknowledgements. This study represents research towards a Ph.D. degree at the University of Western Australia by G.A.K. It was also partly funded by a University of Western Australia Janice Klumpp Award to G.A.K. We thank Ray Masini for constructing the venturi air lift and Anne Brearley, Tim Carruthers and Peter Farrell for their assistance in the field.

\section{LITERATURE CITED}

Amsler, C. D., Searles, R. B. (1980). Vertical distribution of seaweed spores in a water column offshore of North Carolina. J. Phycol 16: 617-619

Anderson, E. K., North, W. J. (1966). In situ studies of spore production and dispersal in the giant kelp, Macrocystis. In: Young, E. G., McLachlan, J. L. (eds.) Proc. 5th int. Seaweed Symp. (Halifax). Pergamon Press, Oxford, p. 73-86

Carlquist, S. (1981). Chance dispersal. Am Sci. 69: 509-516
Chapman, A. R. O. (1985). Demography. In: Littler, M. M., Littler, D. S. (eds.) Handbook of phycological methods IV. Ecological field methods: macroalgae. Cambridge University Press, Cambridge, p. 253-268

Connell, J. H. (1985). The consequences of variation in initial settlement versus post-settlement mortality in rocky intertidal communities. J. exp. mar. Biol. Ecol. 93: 11-45

Critchley, A. T. (1983). The establishment and increase of Sargassum muticum (Yendo) Fensholt populations within the Solent area of southern Britain I. An investigation of the increase in number of population individuals. Botanica mar. 26: 539-545

Critchley, A. T., Farnham, W. F., Morrell, S. L. (1983). A chronology of new European sites of attachment for the invasive brown alga, Sargassum muticum, 1973-1981. J. mar. biol. Ass. U.K. 63: 799-811

DeWreede, R. E. (1983). Sargassum muticum (Fucales, Phaeophyta): regrowth and interactions with Rhodomela larix (Ceramiales, Rhodophyta). Phycologia 22: 153-160

Deysher, L., Norton, T. A. (1982). Dispersal and colonization in Sargassum muticum (Yendo) Fensholt. J. exp. mar. Biol. Ecol. 56: 179-195

Fernandez, C., Guterrez, L. M., Rico, J. M. (1990). Ecology of Sargassum muticum on the north coast of Spain: preliminary observations. Botanica mar. 33: 423-428

Gregory, P. H. (1968). Interpreting plant disease dispersal gradients. Ann. Rev. Phytopathol. 6: 189-212

Hawes, I., Davey, M. C. (1989). Use of the fluorochrome Auramine $\mathrm{O}$ for determination of cell viability in filamentous and thalloid algae. Phycologia 28: 518-520

Hoffman, A. J., Ugarte, R. (1985). The arrival of propagules of marine macroalgae in the intertidal zone. J. exp. mar. Biol. Ecol. 92: 83-95

Hruby, T., Norton, T. A. (1979). Algal colonization on rocky shores in the Firth of Clyde. J. Ecol. 67: 65-77

Jernakoff, P. (1985). Temporal and small-scale spatial variability of algal abundance in an intertidal rocky shore. Botanica mar, 28: 145-154

May, D. I., Clayton, M. N. (1991). Oogenesis, the formation of oogonial stalks and fertilization in Sargassum vestitum (Fucales, Phaeophyta) from southern Australia. Phycologia 30: 243-256

Norton, T. A. (1981). Gamete expulsion and release in Sargassum muticum. Botanica mar. 24: 465-470

Okubo, A., Levin, S. A. (1989). A theoretical framework for data analysis of wind dispersal of seeds and pollen. Ecology 70: 329-338

Paula, E. J., Eston, V. R. (1987). Are there other Sargassum species as potentially invasive as $S$. muticum. Botanica mar. 30: 405-410

Reed, D. C., Laur, D. R., Ebeling, A. W. (1988). Variation in algal dispersal and recruitment: the importance of episodic events. Ecol. Monogr. 58: 321-335

Rice, E. L. (1987). Small-scale distributional pattern in Xiphophora gladiata (Labill.) Mont. ex Kjell. (Fucales, Phaeophyta). Phycologia 26: 246-251

Rice, E. L., Kenchington, T. J. (1990). Spatial variation patterns in the marine macroalga Xiphophora gladiata ssp gladiata (Phaeophyta). I. Partitioning of morphological variation into spatial scales. J. Phycol. 26: 508-522

Schiel, D. R. (1985). Growth, survival and reproduction of two species of marine algae at different densities in natural stands. J. Ecol. 73: 199-217

Schrodter, H. (1960). Dispersal by air and water - the flight and landing. In: Horsfall, J, G., Dimond, A. E. (eds.) Plant pathology, an advanced treatise. Academic Press, New York, p. 170-227 
Sousa, W. P. (1984). Intertidal mosaics: patch size, propagule availability, and spatially variable patterns of succession. Ecology 65: 1918-1935

Umezaki, I. (1984). How many eggs will be discharged from the plant of Sargassum horneri? Hydrobiologia 116/117: 398-402

van den Hoek, C. (1987). The possible significance of long-

This article was submitted to the editor range dispersal for the biogeography of seaweeds. Helgoländer Meeresunters. 41: 261-272

Womersley, H. B. S. (1987). The marine benthic flora of southern Australia. Part II. The flora and fauna of South Australia Handbook Committee, South Australian Government Printers, Adelaide

Manuscript first received: September 16, 1991 Revised version accepted: December 12, 1991 